\title{
CAN ALVEOLAR HYPOVENTILATION DUE TO KYPHOSCOLIOSIS BE A CONTRAINDICATION TO DRIVING?
}

\author{
ALEKSANDER KANIA ${ }^{1}$, PAWEŁ NASTAŁEK ${ }^{1}$, NATALIA CELEJEWSKA-WÓJCIK ${ }^{1}$, KRZYSZTOF SŁADEK ${ }^{1}$, \\ MARCIN KOSOBUDZKI ${ }^{2}$, ALICJA BORTKIEWICZ ${ }^{2}$, and JADWIGA SIEDLECKA ${ }^{2}$ \\ ${ }^{1}$ Jagiellonian University Medical College, Kraków, Poland \\ Faculty of Medicine, II Chair of Internal Medicine, Department of Pulmonology \\ ${ }^{2}$ Nofer Institute of Occupational Medicine, Łódź, Poland \\ Department of Work Physiology and Ergonomics
}

\begin{abstract}
Road accidents are among the main fatalities worldwide and drowsy driving is a significant cause of road deaths where drivers are at fault. There are well known diseases which impair sensory and cognitive functions and can cause sleepiness during driving. Such diseases can be an important contraindication to driving because they may have an adverse effect on its safety. Thus, medical examinations for drivers should also be directed at identifying any possible conditions posing risks for driving safety. Occupational medicine specialists should look for symptoms of locomotor and sleep-related breathing disorders as these are medical conditions which could preclude a person from driving. In this case report, the authors describe a professional driver with chest deformity and present a pioneering attempt at assessing his medical fitness to drive. It is also explained why scoliosis can impair driving ability and how it should be diagnosed and treated. Finally, the authors describe how they used driving simulator tests as part of their diagnosis and suggest a relevant treatment regimen. Int J Occup Med Environ Health. 2019;32(5):735-45
\end{abstract}

Key words:

scoliosis, non-invasive ventilation, professional driving, traffic-related accidents, hypoventilation, sleep apnoea

\section{INTRODUCTION}

It is essential to create an environment for safe transport for citizens around the world. In Europe, the European Commission (EC) is the institution which strives to provide the highest standards of road safety [1]. Road transport is the most widely used means of travel and the primary reason for accidents. The European Union statistics show that the number of traffic-related accidents is gradually decreasing. In 2015, the number of road fatalities was 26000 and that is 5500 fewer than in 2010. According to statistics provided by the EC, as many as 135000 people were severely injured during road accidents in 2016. Social costs (including healthcare) of road accidents resulting in injuries and fatalities are estimated to reach at least EUR 100 billion. Furthermore, it has been shown that trafficrelated death rates have not fallen significantly enough in the past few years. In 2016, in Europe, the road fatality figure reached over 25000 (Figure 1).

Main reasons for traffic-related accidents differ depending on the area of the world but excessive speed and alco-

Received: October 13, 2018. Accepted: May 8, 2019.

Corresponding author: Aleksander Kania, Jagiellonian University Medical College, Faculty of Medicine, II Chair of Internal Medicine, Department of Pulmonology, Skawińska 8, 31-066 Kraków, Poland (e-mail: aleksanderkania@interia.pl). 


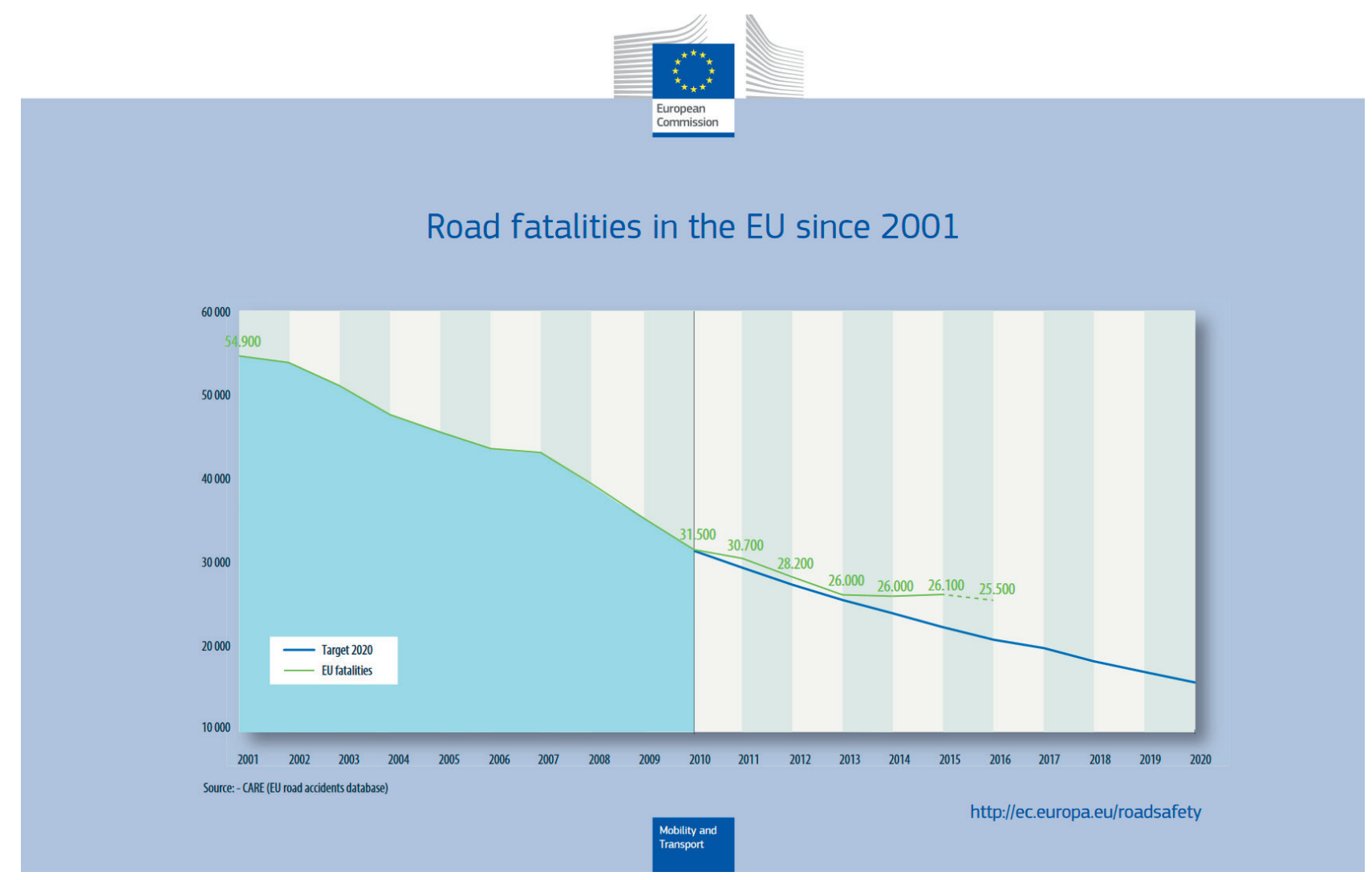

Figure 1. Road fatalities in the EU since 2001

hol consumption still lead the rank. One of the frequent and statistically underrated causes of traffic-related accidents is drowsy driving [2]. As demonstrated by Goncalves et al. in their analysis conducted during a 2-year period in 19 European countries, $17 \%$ of drivers experienced falling asleep at the wheel [3]. Among the respondents who fell asleep, the median prevalence of sleep-related accidents was $7 \%$.

Fatigue and drowsiness result not only from sleep deprivation but also from health issues. Thus, the medical aspect of this phenomenon requires closer attention and becomes a serious challenge for specialists and general practitioners examining their patients' medical fitness to drive. The issue becomes even more significant when it comes to the examination and permits for professional drivers. The current medical knowledge confirms that sleep-related disorders are an important factor which increases the risk of road accidents [4]. These disorders include narcolepsy, sleep apnoea, insomnia, shift work sleep disorder, restless legs syndrome/Willis-Ekbom disease, periodic limb movement disorder and migraine. Therefore, physicians examining professional drivers should possess basic knowledge that would allow them to properly diagnose the above syndromes. Due to the high incidence of some of these disorders, a number of highly-developed countries have issued specific legal acts, the best example of these being European Union Directive 2014/85/EU [5] based on obstructive sleep apnoea (OSA) epidemiology [6,7].

Examination standards for professional drivers also point out other symptoms known to have increased the risk of traffic-related accidents [8]. These conditions include epilepsy, diabetes, cardiac problems, dementia, eyesight dis- 
eases, schizophrenia and others. However, little is being said about musculoskeletal impairments which arise from numerous disorders and trauma like, for instance, amputations, deformities as well as chronic lower back pain. They can impair movement or sensation and affect balance, coordination or power. There is extremely little published data on the risk of road accidents resulting from musculoskeletal disorders [9]. Although several studies refer to patients with an impaired musculoskeletal system who experienced driving difficulties, only a few suggest that these disorders increase the accident risk [10]. This may be due to the fact that drivers are able to compensate for physical impairments while driving. Although chest deformities are quite frequent, their effect on fitness to drive has not been examined in literature to date. Adolescent idiopathic scoliosis (the most frequent form of defect) is a common disease with an overall prevalence of $0.47-5.2 \%$ in the current literature [11].

This article is a case study of a 26-year old professional long-distance truck driver with adolescent idiopathic scoliosis, suffering from hypoventilation and mild sleep apnoea. The main symptoms reported by the patient were a reduced ability to exercise and frequent sleepiness. The patient had undergone a surgical treatment to stop the progression of spine deformity but on admission still showed a considerable degree of scoliosis. The patient's symptoms were proven to be the effect of kyphoscoliosis and the patient was consequently subjected to continuous non-invasive ventilation (NIV) treatment. The aim of this case study is to bring attention to the diagnosis of persons with chest deformities applying for a driving license. The authors also aim at presenting the necessity of introducing a scheme to identify the scale and effects of the analyzed disorder.

\section{CASE REPORT}

In June 2016, a 26-year old patient with advanced kyphoscoliosis and diagnosed bronchial asthma was referred to

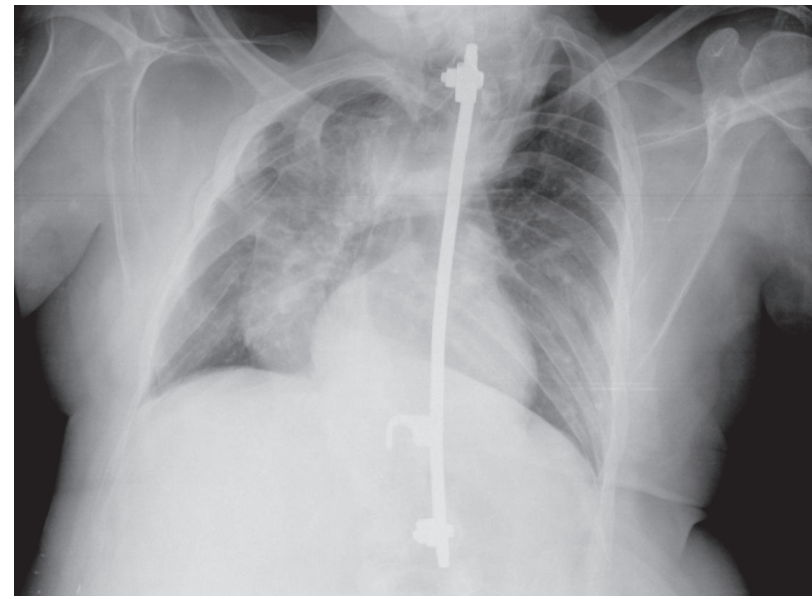

Figure 2. Chest X-ray in PA projection: visible significant scoliosis of the spine and an implant stabilizing it

the Pulmonology Clinic for consultation on the grounds of protracted convalescence after an acute asthma episode in March 2016. The patient was then hospitalized for 3 weeks at a regional internal medicine ward. On admission to the Clinic, the patient complained of permanent weakness, worse physical exercise tolerance and frequent sleepiness. The treatment introduced included fluticasone propionate, $500 \mu \mathrm{g}$ and salmeterol, $50 \mu \mathrm{g}$; theophylline $300 \mathrm{mg} /$ day as well as ipratropium with phenoterol administered 3 times/day in nebulization.

Several years ago, the patient had been operated for kyphoscoliosis. No comorbidities were found in the patient apart from asthma. The patient was a professional longdistance truck driver travelling for business purposes to several European destinations. Despite a visible musculoskeletal deformation, he demonstrated a very good work report and his job constituted an important part of his life as well as a source of personal satisfaction.

The main (and only) abnormality found in the patient during physical examination was a major chest deformation. The patient's arterial blood oxygen saturation measured with pulse oximetry on air breathing was $94 \%$. A chest $\mathrm{X}$-ray was then performed in 2 projections (Figures 2 and 3) and arterial blood gasometry (Table 1). 


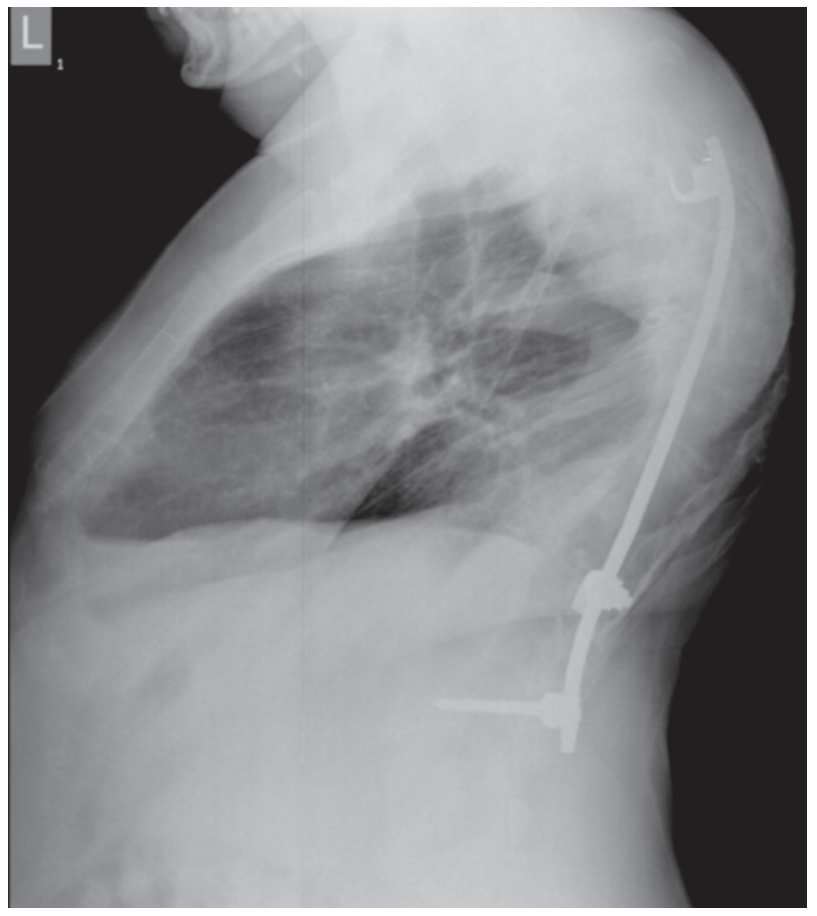

Figure 3. Chest X-ray in left lateral projection: in addition to the deformation and the implant, the correct lung hilum and the normal lung parenchyma are visible

In view of the abnormal gasometry the patient with suspected hypoventilation was referred for further diagnostics to the Pulmonology Clinic. At the Clinic, the patient underwent further diagnostics, i.e., comprehensive blood panel testing, appropriate lung function tests and polysomnography with capnography and arterial blood gas monitoring during sleep, as well as echocardiography.
Spirometry (Table 2) showed reversible obturation, significantly lowered forced vital capacity (FVC), $26 \%$ of the predictive value.

Suspected restriction was confirmed in whole-body air displacement cabin plethysmography (Table 3 ).

Diffusing capacity of the lung for the carbon monoxide test (lung transfer factor for carbon monoxide $-\mathrm{TL}_{\mathrm{CO}}$ ) showed lowered total lung capacity (single breath $\mathrm{TL}_{\mathrm{CO}}-$ $\mathrm{TL}_{\mathrm{CO}} \mathrm{SB} 39.8 \%$ p.v.) with the correct value per alveolar volume (diffusing capacity for carbon monoxide corrected for hemoglobin level per unit alveolar volume $-\mathrm{TL}_{\mathrm{CO}} \mathrm{c} / \mathrm{VA}$ 103\%) (Table 4).

During polysomnography (Tables 5 and 6) only few episodes of sleep apnoea and hypopnea were found. The apnoeahypopnea index (AHI) factor was as low as $6.4 / \mathrm{h}$, but serious deteriorations were found in nocturnal blood oxygenation and blood carbon dioxide level. In accordance with the American Academy of Sleep Medicine (AASM) criteria, hypoventilation syndrome was diagnosed [12]. Furthermore, arterial blood gasometry taken at 2 a.m. showed deepening hypoxia and hypercapnia (Table 1). Alveolar hypoventilation was diagnosed as the effect of thoracic cage disorder. Echocardiography and comprehensive blood tests did not show further disorders. The asthma diagnosis was sustained and the disease was assessed as fully controlled with the asthma control test (ACT) [13] score of 23. Medication was limited to fluticasone propionate, $500 \mu \mathrm{g}$ and

Table 1. Arterial blood gasometry during the day and night before treatment and during non-invasive ventilation treatment in a professional driver with advanced kyphoscoliosis and bronchial asthma in the Pulmonology Clinic in 2016

\begin{tabular}{lccc}
\hline & \multicolumn{3}{c}{ Test result } \\
\cline { 2 - 4 } Parameter & the day before treatment & the night before treatment & $\begin{array}{c}\text { during non-invasive ventilation } \\
\text { treatment }\end{array}$ \\
\hline $\mathrm{pH}$ & 7.39 & 7.34 & 7.41 \\
$\mathrm{pCO}_{2}[\mathrm{~mm} \mathrm{Hg}]$ & 48.2 & 61.9 & 46.0 \\
$\mathrm{pO}_{2}[\mathrm{~mm} \mathrm{Hg}]$ & 68 & 59 & 71 \\
$\mathrm{SO}_{2}[\%]$ & 94.4 & 90.5 & 95.6 \\
$\mathrm{HCO}_{3}^{-}[\mathrm{mmol} / 1]$ & 27.3 & 29.8 & 26.4 \\
\hline
\end{tabular}


Table 2. Spirometry with bronchodilator (BD) reversibility test in a professional driver with advanced kyphoscoliosis and bronchial asthma in the Pulmonology Clinic in 2016

\begin{tabular}{lcccc}
\hline \multirow{2}{*}{ Variable } & \multicolumn{3}{c}{ Spirometry results } \\
\cline { 2 - 5 } & actual & pre-BD & actual & \% predicted \\
\cline { 2 - 5 } & 0.85 & 20.9 & 0.98 & 3.2 \\
\hline $\mathrm{FEV}_{1}[1]$ & 1.27 & 26.6 & 1.25 & -0.5 \\
$\mathrm{FVC}[1]$ & 66.72 & & 78.55 & \\
$\mathrm{FEV}_{1} \% \mathrm{FVC}$ & & &
\end{tabular}

$\mathrm{FEV}_{1}$ - forced expiratory volume in the first second of expiration; $\mathrm{FVC}$ - forced vital capacity.

Table 3. Whole-body air displacement cabin plethysmography in a professional driver with advanced kyphoscoliosis and bronchial asthma in the Pulmonology Clinic in 2016

\begin{tabular}{lccc}
\hline & Variable & \multicolumn{3}{c}{ Whole-body cabin plethysmography results } \\
\cline { 2 - 4 } & actual & \% predicted & percentile \\
\hline RV [1] & 1.37 & 86 & 28 \\
VC [1] & 1.43 & 29 & $<0.01$ \\
TLC [1] & 2.8 & 43 & 0.01 \\
\hline
\end{tabular}

RV - residual volume; TLC - total lung capacity; VC - vital capacity.

salmeterol, $50 \mu \mathrm{g}$ and rescue medication (salbutamol) in the case of dyspnoea.

Since the patient was diagnosed with hypoventilation, NIV therapy was introduced. Two full-night attended polysomnographies were performed for titration to determine the optimal positive airway pressure.

Finally, sleep tests confirmed full normalization of sleep disturbances, which was achieved through bi-level ventilation with average volume assured pressure support (AVAPS): inspiratory positive airway pressure (IPAP) 17 mbar, maximal inspiratory positive airway pressure $\left(\mathrm{IPAP}_{\max }\right) 22$ mbar, tidal volume $\left(\mathrm{V}_{\mathrm{t}}\right) 400 \mathrm{ml}$, expiratory positive airway pressure (EPAP) 6 mbar, breaths per minute (BPM) 15/min, and inspiratory time $\left(\mathrm{T}_{\mathrm{i}}\right) 1.2 \mathrm{~s}$. Ventilation was recommended for at least $8 \mathrm{~h} /$ day and always during sleep. The patient was advised to continue the treatment at home. It was necessary to assess the patient's ability to continue work in view of his occupation. The final decision was to be issued by an occupational health professional but the pulmonologist in charge had to deliver his opinion as to the completion of the treatment and its final effectiveness. The sleepiness level score assessed using the Epworth scale was 3 pts (normal) [14]. Sleep quality assessed with the Pittsburgh Sleep Quality Index was also deemed good,

Table 4. Transfer factor for carbon monoxide in a professional driver with advanced kyphoscoliosis and bronchial asthma in the Pulmonology Clinic in 2016

\begin{tabular}{lcc}
\hline \multirow{2}{c}{ Parameter } & \multicolumn{2}{c}{$\begin{array}{c}\text { Carbon monoxide transfer } \\
\text { factor results }\end{array}$} \\
\cline { 2 - 3 } & actual & $\%$ predicted \\
\hline $\mathrm{TL}_{\mathrm{CO}} \mathrm{SB}[\mathrm{mmol} / \mathrm{min} / \mathrm{kPa}]$ & 4.3 & 38.6 \\
$\mathrm{TL}_{\mathrm{CO}} \mathrm{cSB}[\mathrm{mmol} / \mathrm{min} / \mathrm{kPa}]$ & 4.44 & 39.8 \\
$\mathrm{TL}_{\mathrm{CO}} \mathrm{c} / \mathrm{VA}[\mathrm{mmol} / \mathrm{min} / \mathrm{kPa} / \mathrm{l}]$ & 1.76 & 103 \\
\hline $\mathrm{TL}_{\mathrm{CO}}-$ lung transfer factor for carbon monoxide; $\mathrm{TL}_{\mathrm{CO}} \mathrm{c} / \mathrm{VA}-$ diffusing \\
capacity for carbon monoxide corrected for the hemoglobin level per \\
unit alveolar volume; $\mathrm{SB}$ - single breath.
\end{tabular}


Table 5. Polysomnography report - an excerpt (saturation values) in a professional driver with advanced kyphoscoliosis and bronchial asthma in the Pulmonology Clinic in 2016

\begin{tabular}{lcccc}
\hline \multirow{2}{*}{ Parameter } & \multicolumn{4}{c}{ Blood oxygen saturation } \\
\cline { 2 - 5 } & awake & NREM & REM & TIB \\
\hline Desaturations [n] & 0 & 54 & 11 & 65 \\
Index $[1 / \mathrm{h}]$ & 0.0 & 40.5 & 42.0 & 40.8 \\
Average $\mathrm{SpO}_{2} \%$ & 87 & 84 & 91 & 86 \\
\hline
\end{tabular}

NREM - non-rapid eye movement; REM - rapid eye movement; TIB - time in bed

Table 6. Patients' polysomnography report - an excerpt (saturation sections) in a professional driver with advanced kyphoscoliosis and bronchial asthma in the Pulmonology Clinic in 2016

\begin{tabular}{rcccccccc}
\hline \multirow{2}{*}{$\begin{array}{c}\mathrm{SpO}_{2} \\
\text { range } \\
\text { of values }\end{array}$} & \multicolumn{7}{c}{$\begin{array}{c}\text { Blood oxygen saturation } \\
\text { (in time) }\end{array}$} \\
\cline { 2 - 9 } & \multicolumn{2}{c}{ awake } & \multicolumn{7}{c}{ NREM } & \multicolumn{2}{c}{ REM } & TST \\
\hline$<95 \%$ & 7.4 & 2.3 & 80.0 & 25.2 & 15.7 & 5.0 & 103.1 & 32.5 \\
$<90 \%$ & 7.4 & 2.3 & 68.5 & 21.6 & 1.8 & 0.6 & 77.7 & 24.5 \\
$<85 \%$ & 0.6 & 0.2 & 19.1 & 6.0 & 0.0 & 0.0 & 19.7 & 6.2 \\
$<80 \%$ & 0.0 & 0.0 & 16.0 & 5.0 & 0.0 & 0.0 & 16.0 & 5.0 \\
$<75 \%$ & 0.0 & 0.0 & 10.4 & 3.3 & 0.0 & 0.0 & 10.4 & 3.3 \\
$<70 \%$ & 0.0 & 0.0 & 5.8 & 1.8 & 0.0 & 0.0 & 5.8 & 1.8 \\
$<60 \%$ & 0.0 & 0.0 & 0.3 & 0.1 & 0.0 & 0.0 & 0.3 & 0.1 \\
$<50 \%$ & 0.0 & 0.0 & 0.0 & 0.0 & 0.0 & 0.0 & 0.0 & 0.0 \\
\hline
\end{tabular}

NREM - non-rapid eye movement; REM - rapid eye movement; TST - total sleep time.

showing a score of $3[15]$. However, the above results were not sufficient for the pulmonologist in charge who was unsure as to what extent the patient's condition could affect his cognitive ability. Consequently, the patient was sent on a further sick leave, and was to present for check-up and sleep tests in 6 weeks. The patient felt well while on the sick leave. During the check-up, the respirator memory card was read and analyzed. The patient's compliance with therapy was confirmed and so was the positive therapeutic outcome: there were no breathing disorders during sleep (AHI 2.4/h) and ventilation was smooth. The mean maximal expiratory volume (tidal volume expiration maximal $\mathrm{VTe}_{\max }$ ) was $497 \mathrm{ml}$.
The patient was subjected to check-up sleep diagnosis consisting of capnometry and arterial blood gasometry which showed that all symptoms were under control as a result of NIV. Nonetheless, the situation of the patient still seemed unclear, unlike, e.g., in the case of a patient with simple apnoea treated with continuous positive airway pressure (CPAP) who could have been recommended to resume working as a driver. For this reason, advice was sought from occupational health professionals who recommended that the patient take a truck drive simulator test which would reflect his driving ability. The test consisted of city driving, driving on country roads and in the mountains during moderate traffic. The simulation showed differ- 
ent weather conditions: summer, winter, strong wind and heavy rain. The test also incorporated stressful situations such as cutting off by another vehicle (at a roundabout), driving on narrow streets and sudden steering wheel jerk. The simulation included a manual and automatic gearbox. Furthermore, the patient's ability (skill) to start the engine, switch on the lights, indicators and other controls on the steering column was tested. The study time was $40 \mathrm{~min}$. The study protocol included driving on easy and difficult routes, and provided situations requiring a fast driver's reaction. Figure 4 shows AUTOSAN LIDER 1010T bus simulator and a view of the operator station.

An actual bus cabin is mounted on a movable platform, simulating the movements of the bus under real-world conditions. The visualization system of the simulator generates and displays a realistic view as seen from the cabin of the vehicle. This allows the examined driver to see the road and its environment in a manner similar to the real circumstances. The result of the test did not provide any argument against the patient resuming his professional activity. Since the patient was recommended to use the respirator every night and as this would be rather difficult to achieve for a long-distance driver, he was advised to drive only on short routes so that he would be able to spend nights at home and use the device. This has discouraged the patient from resuming work as a driver. He is now working in a restaurant and considering becoming a courier so that he can drive more again.

\section{DISCUSSION}

The present case study is the first, to the best of the authors' knowledge, that refers to a professional long-distance driver suffering from kyphoscoliosis resulting in hypoventilation and sleep-related breathing disorders. This is also the first instance when a driving simulator was used to assess the ability to drive vehicles in a patient with scoliosis. This study presents the patient's imaging and breathing function test results. The study also shows that

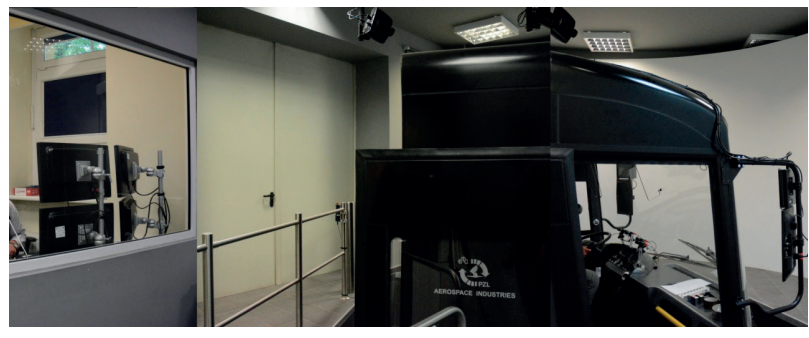

Photo: Zbigniew Jóźwiak

Figure 4. AUTOSAN LIDER 1010T bus simulator

a diagnosis of the lung function based on blood oxygen saturation only can be misleading. The authors describe the treatment introduced and present a pioneering approach towards the medical approval of a driving permit for professional drivers who require NIV therapy. Finally, they also prove that some patients undergoing NIV can have an active professional life and continue driving.

Among the reasons behind driving restrictions connected with musculoskeletal deformations, hypoventilation in drivers has been previously overlooked. The medical standards for driving permits also do not mention a higher incidence of sleep apnoeas resulting from kyphoscoliosis. However, already at the turn of the 1970s, some studies mentioned that musculoskeletal deformations could be predictors of sleep breathing disorders $[16,17]$. Guilleminault et al. described a possibility of several sleep breathing disorders in subjects with severe chest deformation and called it the Quasimodo syndrome during sleep [18]. Further studies confirmed how important it was to look for and treat sleep breathing issues such as apnoeas and hypoventilation in patients suffering from kyphoscoliosis, chronic obstructive pulmonary disease (COPD) or neuromuscular disorders [19]. It is also known that sleep disorders such as apnoeas and alveolar hypoventilation can impair concentration, thus becoming a risk factor for a road traffic accident $[4,20,21]$.

Initial stages of hypoventilation with mild to moderate hypercapnia are usually asymptomatic or show only minimal symptoms. Patients may complain of anxiety and dyspnoea 
with exertion. With an increase in the degree of hypoventilation, they develop dyspnoea at rest. Some may experience disturbed sleep and daytime hypersomnolence while others may further develop increased hypercapnia and hypoxemia. It is important to emphasize that most patients develop hyperventilation during night and only later experience symptoms during daytime [22]. Such a situation can initially affect mainly the structure of sleep and impair its quality. This pathomechanism may be of key importance in increasing the risk of falling asleep while driving.

The patient studied showed typical hypoventilation symptoms, and his tiredness as well as muscular weakness were wrongly interpreted as asthma exacerbation-related problems. Probably the viral infection which led to asthma exacerbation became a mechanism which triggered off earlier mild hypoventilation. Also, transcutaneous blood oxygen saturation measurement could have been misleading here because the $94 \%$ result could wrongly suggest that the patient experienced no lung function impairment. It is worth to point out here that even an arterial blood saturation test does not fully correlate with partial pressure of oxygen [23]. Thus, an arterial blood gasometry test was a crucial diagnostic decision because it confirmed hypercapnia and consequent hypoxemia. The result of the test showed an increased $\mathrm{HCO}_{3}^{-}$value which was caused by metabolic compensation of breathing acidosis resulting from hypoventilation. The level of $\mathrm{HCO}_{3}^{-}$is a good parameter for judging the risk of hypoventilation. This observation is known mainly from hypoventilation analyses in obese subjects [24]. It is assumed that a $\mathrm{HCO}_{3}^{-}>27 \mathrm{mmol} / \mathrm{l}$ significantly increases the probability of hypoventilation. This patient's result was $\mathrm{HCO}_{3}^{-}=27.3 \mathrm{mmol} / \mathrm{l}$.

There are known cases in literature which show how to look for hypoventilation risks and lung function impairment resulting from kyphoscoliosis. One of these is the Cobb angle - a measure that describes the degree of spinal deformation [16]. It is assumed that a Cobb angle value $>70^{\circ}$ significantly reduces lung area, $>100^{\circ}$ results in apnoea, and $>120^{\circ}$ is directly related to hypoventilation and respiratory failure [25]. In the patient under analysis, the Cobb angle was $140^{\circ}$. The basic spirometry test is another valuable tool that allows estimating the risk of respiratory failure. A vital capacity (VC) score $<43 \%$ is a significant predictor of respiratory failure [26]. This patient's FVC score was only $26 \%$.

A full polysomnography is the best test to detect night hypoventilation. In accordance with the AASM guidelines, the key parameter here is the $\mathrm{CO}_{2}$ level measurement [12]. During the REM sleep phase, patients usually experience the most acute hypoventilation. When trying to determine the reasons for this problem, the authors noticed that the REM phase in the patient under analysis was rather short. Before one of the REMs, the patient woke up and stayed awake for about $20 \mathrm{~min}$ so that his oxygenation could improve (capnia was reduced). Then, he fell asleep and easily went into REM. This reserve is hence one of the mechanisms which could explain his good saturation throughout the REM. The following REM was typical but short. Therefore, the patient's results may be misleading if only the mean values are considered. The decision to implement NIV treatment resulted from the authors' factual knowledge.

It is known that no other respiratory failure treatment method in kyphoscoliosis is more effective than NIV [27]. Such treatment in patients with kyphoscoliosis not only increases the survival rate [28], but also improves gasometry, reduces hypoventilation symptoms and has a beneficial impact on muscle function [29]. It is a good clinical practice to confirm the treatment efficacy in a control sleep test [30]. There are several scales and questionnaires used to predict the risks or evaluate the degree of symptoms connected with sleep apnoea [31]. Nonetheless, little is known as far as their efficacy in reference to hypoventilation is concerned. For this reason, a decision to issue a driving permit to patients with hypoventilation becomes more difficult. The authors decided to use an advanced driving simulator as a diagnostic tool because they wanted to en- 
sure that their decision as to the patient was a safe one. Although many questions still need to be answered before advanced simulators can be used to help in the assessment of the ability to drive in patients with OSA, the perspective seems promising [32]. The authors also know now how well driving simulator tests can help identify changes in driving capacity in subjects not treated for sleeping disorders [33]. Furthermore, there are also studies in which simulator tests have been used to show that after a few days' CPAP treatment the patients' abilities improved considerably [34]. It is not necessary to reduce the normal activity for patients treated with NIV. Some of them can lead an active professional life. In the presented case, the decision was more difficult since it would not be possible for the patient to get NIV treatment while travelling longdistance. Respirators are not portable medical devices and thus therapy should be conducted in 1 place.

The authors realize that it is a singular case study and that conclusions regarding driving safety for persons with hypoventilation resulting from kyphoscoliosis cannot be drawn based on the analysis presented. The presented case has some limitations, one of them being the lack of a driving simulator test before and during the NIV treatment in the patient. The described diagnostic and therapeutic scheme is only a proposed one and it has its limitations, such as the limited availability of driving simulator tests.

In recent years, the assessment of the psychophysical abilities of drivers with sleep disorders has been broadened with the use of driving simulators that quite accurately imitate real driving conditions. This approach allows assessing the driver's reactions and behaviors in different situations on the road, including the most dangerous ones. A comparison of the simulator results with real-life ones will make it possible to judge to what extent the risk of an accident in simulated conditions is correlated with the risk of an accident in real-world settings [35-37]. Unfortunately, not so many medical centers are equipped with as advanced simulators [38] as the one used in this study.

\section{CONCLUSIONS}

A patient with kyphoscoliosis can suffer from hypoventilation and sleep breathing disorders. Hypoventilation and/or sleep apnoeas in kyphoscoliosis can be considered a contraindication to driving vehicles. Therefore, persons with significant scoliosis and accompanying breathing disorders, when applying for a medical certificate for drivers, should be consulted by specialists in this type of illness. In the case of a high degree of scoliosis, low spirometric values or clinical signs of breathing disorders during sleep, patients should be referred to pulmonologists in order to exclude hypoventilation and apnoeas during sleep. To this end, it is necessary to implement a full specialist diagnosis including polysomnography and capnometry. This knowledge should be publicized among physicians responsible for assessing their patients' medical fitness to drive. Confirmed hypoventilation in kyphoscoliosis is an indication to implement NIV treatment. An efficiently treated and controlled hypoventilation can allow the patient to function and work normally. The specificity of NIV treatment, however, does not enable treatment outside patients' home environment.

The use of simulator tests in the diagnostic process can significantly improve not only the driver evaluation scheme but also the specialist assessment of the patients' ability to drive. The availability of this method is still limited but it can be helpful to occupational medicine specialists in diagnosing specific cases of patients whose ability to drive cannot be assessed in other tests.

\section{REFERENCES}

1. European Commission [Internet]. Mobility and transport. European Commission; 2018 [cited 2018 May 11]. Available from: https://ec.europa.eu/transport/themes/security_en.

2. Lyznicki JM, Doege TC, Davis RM, Williams MA. Sleepiness, driving, and motor vehicle crashes. Council on Scientific Affairs, American Medical Association. JAMA. 1998;279(23):1908-13. 
3. Goncalves M, Amici R, Lucas R, Akerstedt T, Cirignotta F, Horne J, et al. Sleepiness at the wheel across Europe: a survey of 19 countries. J Sleep Res. 2015;24(3):242-53, https:// doi.org/10.1111/jsr.12267.

4. Liu SY, Perez MA, Lau N. The Impact of Sleep Disorders on Driving Safety - Findings from the SHRP 2 Naturalistic Driving Study. Sleep. 2018:41(4):1-11, https://doi. org/10.1093/sleep/zsy023.

5. Bonsignore MR, Randerath W, Riha R, Smyth D, Gratziou $\mathrm{C}$, Goncalves $\mathrm{M}$, et al. New rules on driver licensing for patients with obstructive sleep apnea: European Union Directive 2014/85/EU. J Sleep Res. 2016;25(1):3-4, https://doi. org/10.1111/jsr.12379.

6. Punjabi NM. The epidemiology of adult obstructive sleep apnea. Proc Am Thorac Soc. 2008;5(2):136-43, https://doi. org/10.1513/pats.200709-155MG.

7. Garvey JF, Pengo MF, Drakatos P, Kent BD. Epidemiological aspects of obstructive sleep apnea. J Thorac Dis. 2015;7(5):920-9, https://doi.org/10.3978/j.issn.2072-1439. 2015.04.52.

8. Dischinger PC, Ho SM, Kufera JA. Medical conditions and car crashes. Annu Proc Assoc Adv Automot Med. 2000;44:335-46.

9. Vernon DD, Diller EM, Cook LJ, Reading JC, Suruda AJ, Dean JM. Evaluating the crash and citation rates of Utah drivers licensed with medical conditions, 1992-1996. Accid Anal Prev. 2002;34(2):237-46.

10. Koepsell TD, Wolf ME, McCloskey L, Buchner DM, Louie D, Wagner EH, et al. Medical conditions and motor vehicle collision injuries in older adults. J Am Geriatr Soc. 1994;42(7):695-700.

11. Konieczny MR, Senyurt H, Krauspe R. Epidemiology of adolescent idiopathic scoliosis. J Child Orthop. 2013;7(1):3-9, https://doi.org/10.1007/s11832-012-0457-4.

12. Berry RB, Brooks R, Gamaldo C, Harding SM, Lloyd RM, Quan SF, et al. AASM Scoring Manual Updates for 2017 (Version 2.4). J Clin Sleep Med. 2017;13(5):665-6, https:// doi.org/10.5664/jcsm.6576.
13. Nathan RA, Sorkness CA, Kosinski M, Schatz M, Li JT, Marcus P, et al. Development of the asthma control test: a survey for assessing asthma control. J Allergy Clin Immunol. 2004;113(1):59-65, https://doi.org/10.1016/j.jaci.2003. 09.008 .

14. Johns MW. A new method for measuring daytime sleepiness: the Epworth sleepiness scale. Sleep. 1991;14(6):540-5.

15. Buysse DJ, Reynolds CF 3rd, Monk TH, Berman SR, Kupfer DJ. The Pittsburgh Sleep Quality Index: a new instrument for psychiatric practice and research. Psychiatry Res. 1989;28(2):193-213.

16. Bergofsky EH. Respiratory failure in disorders of the thoracic cage. Am Rev Respir Dis. 1979;119(4):643-69, https:// doi.org/10.1164/arrd.1979.119.4.643.

17. Mezon BL, West P, Israels J, Kryger M. Sleep breathing abnormalities in kyphoscoliosis. Am Rev Respir Dis. 1980; 122(4):617-21, https://doi.org/10.1164/arrd.1980.122.4.617.

18. Guilleminault C, Kurland G, Winkle R, Miles LE. Severe kyphoscoliosis, breathing, and sleep: the "Quasimodo" syndrome during sleep. Chest. 1981;79(6):626-30.

19. Millman RP, Kramer NR. Sleep disorders and outpatient treatment of patients with pulmonary disease. Curr Opin Pulm Med. 1996;2(6):507-12.

20. Ayas N, Skomro R, Blackman A, Curren K, Fitzpatrick M, Fleetham J, et al. Obstructive sleep apnea and driving: A Canadian Thoracic Society and Canadian Sleep Society position paper. Can Respir J. 2014;21(2):114-23.

21. Piper AJ, Yee BJ. Hypoventilation syndromes. Compr Physiol. 2014;4(4):1639-76, https://doi.org/10.1002/cphy.c140008.

22. Clinical Indications for Noninvasive Positive Pressure Ventilation in Chronic Respiratory Failure Due to Restrictive Lung Disease, COPD, and Nocturnal Hypoventilation A Consensus Conference Report. Chest. 1999;116(2):52134, https://doi.org/10.1378/chest.116.2.521.

23. Gothgen IH, Siggaard-Andersen O, Kokholm G. Variations in the hemoglobin-oxygen dissociation curve in 10079 arterial blood samples. Scand J Clin Lab Invest Suppl. 1990;203:87-90. 
24. Macavei VM, Spurling KJ, Loft J, Makker HK. Diagnostic predictors of obesity-hypoventilation syndrome in patients suspected of having sleep disordered breathing. J Clin Sleep Med. 2013;9(9):879-84, https://doi.org/10.5664/jcsm.2986.

25. Koumbourlis AC. Scoliosis and the respiratory system. Paediatr Respir Rev. 2006;7(2):152-60, https://doi.org/10.1016/ j.prrv.2006.04.009.

26. Pehrsson K, Bake B, Larsson S, Nachemson A. Lung function in adult idiopathic scoliosis: a 20 year follow up. Thorax. 1991;46(7):474-8.

27. Pajdzinski M, Mlynarczyk P, Milkowska-Dymanowska J, Bialas AJ, Afzal MAM, Piotrowski WJ, et al. Kyphoscoliosis what can we do for respiration besides NIV? Adv Respir Med. 2017;85(6):352-8, https://doi.org/10.5603/ARM.2017.0060.

28. Gustafson T, Franklin KA, Midgren B, Pehrsson K, Ranstam J, Strom K. Survival of patients with kyphoscoliosis receiving mechanicalventilation or oxygen at home. Chest. 2006;130(6): 1828-33, https://doi.org/10.1378/chest.130.6.1828.

29. Gonzalez C, Ferris G, Diaz J, Fontana I, Nunez J, Marin J. Kyphoscoliotic ventilatory insufficiency: effects of longterm intermittent positive-pressure ventilation. Chest. 2003;124(3):857-62.

30. Berry RB, Chediak A, Brown LK, Finder J, Gozal D, Iber C, et al. Best clinical practices for the sleep center adjustment of noninvasive positive pressure ventilation (NPPV) in stable chronic alveolar hypoventilation syndromes. J Clin Sleep Med. 2010;6(5):491-509.

31. Pataka A, Daskalopoulou E, Kalamaras G, Fekete Passa K, Argyropoulou P. Evaluation of five different questionnaires for assessing sleep apnea syndrome in a sleep clinic.
Sleep Med. 2014;15(7):776-81, https://doi.org/10.1016/j. sleep.2014.03.012.

32. Ghosh D, Jamson SL, Baxter PD, Elliott MW. Continuous measures of driving performance on an advanced officebased driving simulator can be used to predict simulator task failure in patients with obstructive sleep apnoea syndrome. Thorax. 2012;67(9):815-21, https://doi.org/10.1136/ thoraxjnl-2011-200699.

33. May JF, Porter BE, Ware JC. The deterioration of driving performance over time in drivers with untreated sleep apnea. Accid Anal Prev. 2016;89:95-102, https://doi.org/10.1016/j.aap. 2016.01.002.

34. Turkington PM, Sircar M, Saralaya D, Elliott MW. Time course of changes in driving simulator performance with and without treatment in patients with sleep apnoea hypopnoea syndrome. Thorax. 2004;59(1):56-9.

35. Pizza F, Contardi S, Mondini S, Trentin L, Cirignotta F. Daytime sleepiness and driving performance in patients with obstructive sleep apnea: comparison of the MSLT, the MWT, and a simulated driving task. Sleep. 2009;32(3):382-91.

36. Juniper M, Hack MA, George CF, Davies RJ, Stradling JR. Steering simulation performance in patients with obstructive sleep apnoea and matched control subjects. Eur Respir J. 2000;15(3):590-5.

37. Boyle LN, Tippin J, Paul A, Rizzo M. Driver Performance in the Moments Surrounding a Microsleep. Transp Res Part F Traffic Psychol Behav. 2008;11(2):126-36, https://doi. org/10.1016/j.trf.2007.08.001.

38. Lozia Z. Symulatory jazdy samochodem. Warszawa: Wydawnictwa Komunikacji i Łączności; 2008. Polish.

This work is available in Open Access model and licensed under a Creative Commons Attribution-NonCommercial 3.0 Poland License - http://creativecommons.org/ licenses/by-nc/3.0/pl/deed.en. 